\title{
What Can a Translation Machine Do in Translating Abbreviations in Source Language Text into Target Language Text?
}

\author{
Abdul Muth'im \\ English Language Education Study Program \\ Faculty of Teacher Training and Education \\ Universitas Lambung Mangkurat, Banjarmasin, Indonesia
}

\begin{abstract}
The main question that neeeds to be answered in this study was "What can a Translation Machine do in translating abbreviations in source language text into target language text?" The research method used in this study was descriptive qualitative. The source of data were 5 five Indonesian abstracts written by master degree students of different study programs in Indonesia as the SLT. The abstracts were then translated into English using Translation Machine as TLT. The results show that in translating abbreviations found in SLT a Translation Machine did different performances in TLT: (a) keeping the abbreviations the same if the abbreviations in SLT are not preceeded or followed by any hint or clue, (b) translating the abbreviations if the abbreviations in SLT are preceeded or followed by any hint or clue.
\end{abstract}

Keywords: Source language text, target language text, translating, translation machine

Cite as: Muth'im, A (2018). What Can a Translation Machine Do in Translating Abbreviations in Source Language Text into Target Language Text?. Arab World English Journal for Translation \& Literary Studies, 2 (3). DOI: http://dx.doi.org/10.24093/awejtls/vol2no3.6 